\title{
Advances in clinical applications of cardiovascular magnetic resonance imaging
}

\author{
W P Bandettini, A E Arai
}

Laboratory of Cardiac Energetics, National Heart, Lung, and Blood Institute, National Institutes of Health, Bethesda, Maryland, USA

Correspondence to: W Patricia Bandettini, Laboratory of Cardiac Energetics, National Heart, Lung, and Blood Institute, National Institutes of Health,

Building 10, Room BID416, MSC 1061, 10 Center Dr, Bethesda, MD 20892-1061, USA; ingkanisorn@nih.gov

Accepted 8 January 2008 Published Online First 20 January 2008

\section{ABSTRACT}

Cardiovascular magnetic resonance (CMR) is an evolving technology with growing indications within the clinical cardiology setting. This review article summarises the current clinical applications of CMR. The focus is on the use of CMR in the diagnosis of coronary artery disease with summaries of validation literature in CMR viability, myocardial perfusion, and dobutamine CMR. Practical uses of CMR in non-coronary diseases are also discussed.

The purpose of this review is to illustrate that cardiovascular magnetic resonance (CMR) has developed into a powerful non-invasive diagnostic tool that can routinely image myocardial anatomy, function, perfusion, and viability without need for ionising radiation.

\section{BASIC HARDWARE}

Fundamentally, CMR uses a magnet 30000 to 60000 times the strength of the Earth's magnetic field to detect the location and physical properties of protons in the body. CMR requires fast gradients, phased-array coils, cardiac gating, and cardiovascular software. Higher magnet field strength (3T vs $1.5 \mathrm{~T}$ ) improves signal-to-noise but exacerbates problems related to field inhomogeneity and specific absorption of radiation, factors leading to artifacts and patient heating respectively. The gradients encode many aspects of the image including position in the body, velocity of blood, and other parameters. Phased-array coils act as antennae to receive the tiny MRI-related radiofrequency signals emanating from the body. Phased-array coils enable image acquisition acceleration with parallel imaging methods. ${ }^{1-3}$

Stress testing requires MRI-compatible intravenous pumps, contrast injectors, patient monitoring equipment, resuscitation equipment, and audiovisual equipment to communicate with the patient. The clinical team must be prepared to quickly remove a patient from the scanner and treat cardiovascular emergencies.

\section{CONTRAINDICATIONS}

The magnetic fields, gradients, and radiofrequency pulses used in MRI pose risks to patients and staff, requiring meticulous safety procedures. Ferromagnetic materials should not be taken into the scanner room. Neurovascular clips, pacemakers, automatic implantable defibrillators, cochlear implants, metal in the eye, retained shrapnel, and neurostimulators are contraindications to MRI although certain models may be safe. With CMR imaging, it is important to note that intracoronary stents and coronary artery bypass graft surgery are not contraindications. ${ }^{4}$ Although small forces are generated within metal heart valves by the magnetic fields, they are minimal compared with the forces generated by the beating heart, and all mechanical heart valves are considered safe. When in doubt, various resources, such as www.imrser.org and www.mrisafety.com, ${ }^{5}$ are available to check a device's safety within an MRI scanner. ${ }^{6-9}$

\section{WHAT CMR CAN DO}

\section{Assessment of right and left ventricular function and mass}

Assessment of left ventricular size, function and mass has been well validated in both autopsy and animal studies, ${ }^{10-12}$ and has excellent intraobserver and interobserver variability. ${ }^{13-18}$ This reproducibility allows for smaller sample size in studies requiring serial exams than other lower-resolution imaging such as echocardiography.

CMR can quantify regional wall motion and myocardial strain with techniques such as the harmonic phase method (HARP), ${ }^{19}$ displacement encoding with stimulated echoes (DENSE), ${ }^{20}{ }^{21}$ and spatial modulation magnetisation (SPAMM). ${ }^{22}$ These techniques can assess myocardial strain independent of the effects of through-plane motion.

Real-time CMR can be used in situations where cardiac gating is not currently feasible. One example is the prenatal assessment of fetal cardiovascular abnormalities. ${ }^{23}$

\section{Diagnosis of coronary artery disease}

A single CMR study can provide information regarding the coronary arteries, left ventricular systolic function, myocardial perfusion, and viability (fig 1).

\section{Viability assessment}

One of the major breakthroughs for the use of CMR was the development of gadolinium delayed enhancement techniques to assess for myocardial infarction. ${ }^{24}$ Gadolinium shortens tissue T1 relaxation time, a magnetic property inherent to all tissues. The operator can select an inversion time that will "null" normal myocardium resulting in images where viable myocardium appears uniformly dark while a region of myocardial infarction or fibrotic scar appears bright (fig 2). Dysfunctional but viable myocardium is expected to have functional recovery if revascularised (in the case of hibernating myocardium), with time (in the case of stunned myocardium), or with resynchronisation (in the case of dyssynchronous myocardium). 
Figure 1 Comprehensive cardiovascular magnetic resonance with cine function, dipyridamole perfusion, and delayed enhancement: A 77-year-old man presents with exertional angina and a past medical history significant for hypertension and a prior stroke. In the top row, cine function demonstrates normal global and regional left ventricular systolic function. The dipyridamole perfusion image on the lower left panel demonstrates a severe perfusion defect in a multivessel coronary distribution, while the delayed enhancement image on the right lower panel demonstrates only a small subendocardial myocardial infarction of the inferoseptal wall, indicating a large ischaemic region with a large territory of viable myocardium.
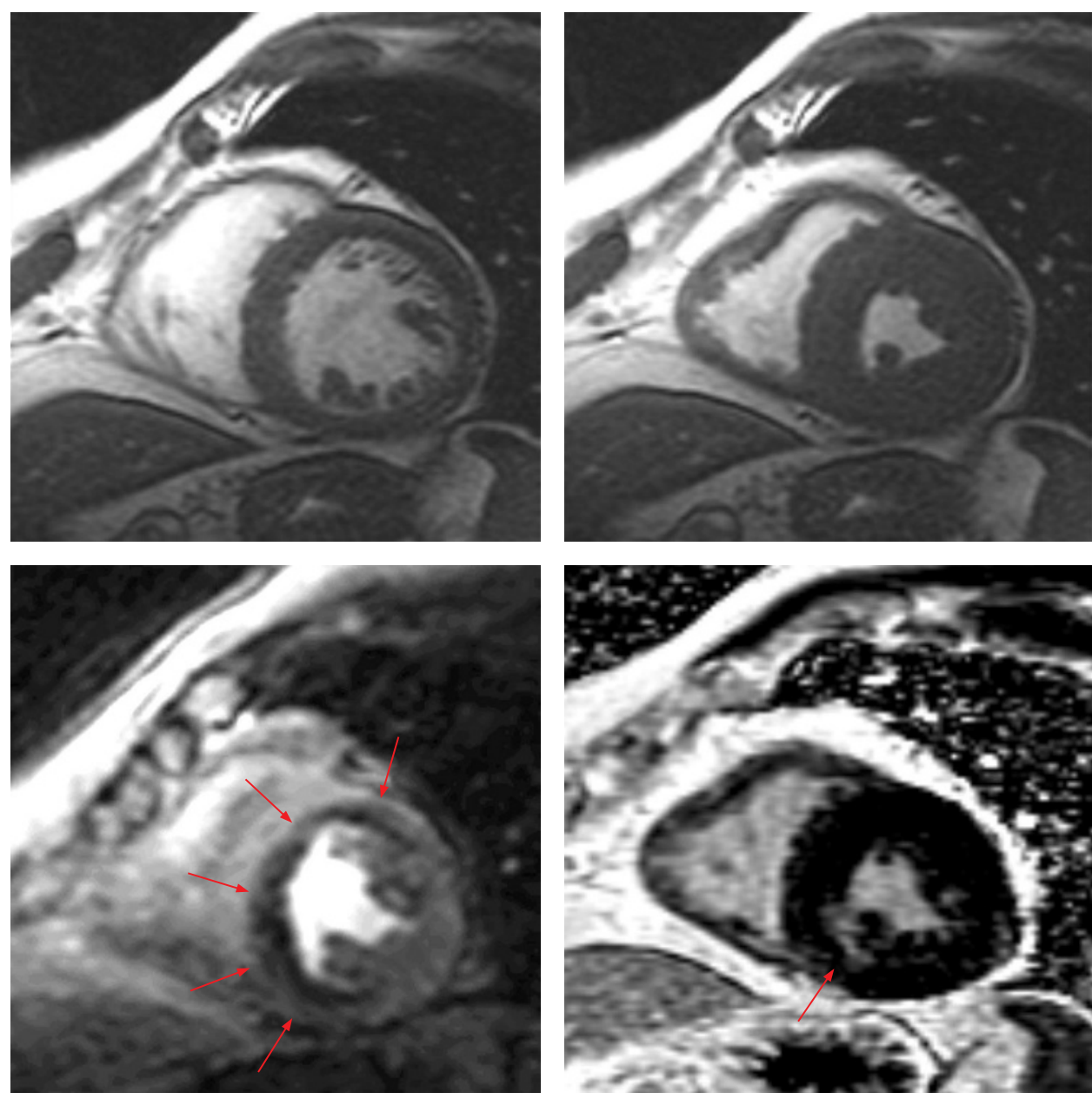

In a seminal paper by Kim et al, the delayed enhancement of myocardial infarction by CMR closely correlated with the histopathological triphenyltetrazolium chloride (TTC) findings. ${ }^{25}$ Multiple studies have demonstrated the inverse relationship between the transmural extent of myocardial infarction and recovery of function, the higher spatial resolution of this technique compared with nuclear techniques, as well as the good correlation with biomarkers of necrosis. ${ }^{26-48}$ The reproducible nature of the delayed enhancement technique also makes it a natural choice for serial imaging of chronic infarctions. ${ }^{40}$

\section{Myocardial perfusion}

Myocardial perfusion has been a CMR research focus. The challenge has been obtaining enough signal, temporal resolution, spatial resolution, and spatial coverage, while minimising artifacts. Most groups use fast gradient recalled echo (FGRE), FGRE with echoplanar imaging (Hybrid EPI), and steady state free precession (SSFP) perfusion techniques, typically using adenosine or dipyridamole as the stressor. These sequences may be accelerated with parallel imaging techniques and performed with multiple gadolinium dosing schemes. The studies may be interpreted qualitatively, semi-quantitatively, or quantitatively. Despite the technical issues related to perfusion imaging, many papers document that CMR first-pass perfusion has comparable diagnostic accuracy to the alternative myocardial perfusion imaging standards. ${ }^{49-70}$

\section{Dobutamine CMR}

Dobutamine stress CMR was first described in the same year that dobutamine stress echocardiography was described. ${ }^{71}$
Dobutamine CMR has good sensitivity and specificity in the detection of significant coronary artery disease (table 1) with a safety profile similar to dobutamine echocardiography. ${ }^{72}$ While the sensitivity and specificity of CMR are comparable to stress echocardiography in patients with good echocardiographic windows, CMR performs better than stress echocardiography in patients with suboptimal echocardiographic windows. ${ }^{73-78}$ Furthermore, dobutamine stress CMR has prognostic value above and beyond the baseline ejection fraction. ${ }^{79} 80$

\section{Acute chest pain in the hospital setting}

Three major papers have looked at use of CMR in patients with acute coronary syndrome (ACS) or early diagnosis of chest pain in the emergency department. In a study of 161 patients presenting with chest pain not associated with ST elevation, Kwong et al found that CMR had $100 \%$ sensitivity for non-ST elevation myocardial infarction and was a better predictor of ACS than standard clinical tests including the composite TIMI risk score. ${ }^{81}$ In a higher risk group of 68 patients with possible or probable ACS scheduled for coronary angiography, Plein et al found that a multicomponent CMR consisting of cine function, adenosine and rest perfusion, delayed enhancement, and coronary artery imaging yielded a sensitivity of $96 \%$ and a specificity of $83 \%$ in predicting the presence of significant coronary artery disease. ${ }^{64}$ In another emergency department study of 141 patients with myocardial infarction excluded by serial troponin assays, Ingkanisorn et al found that adenosine stress CMR had excellent prognostic value as $100 \%$ of patients with adverse cardiovascular outcomes were detected with an overall specificity of $91 \%{ }^{54}$ 

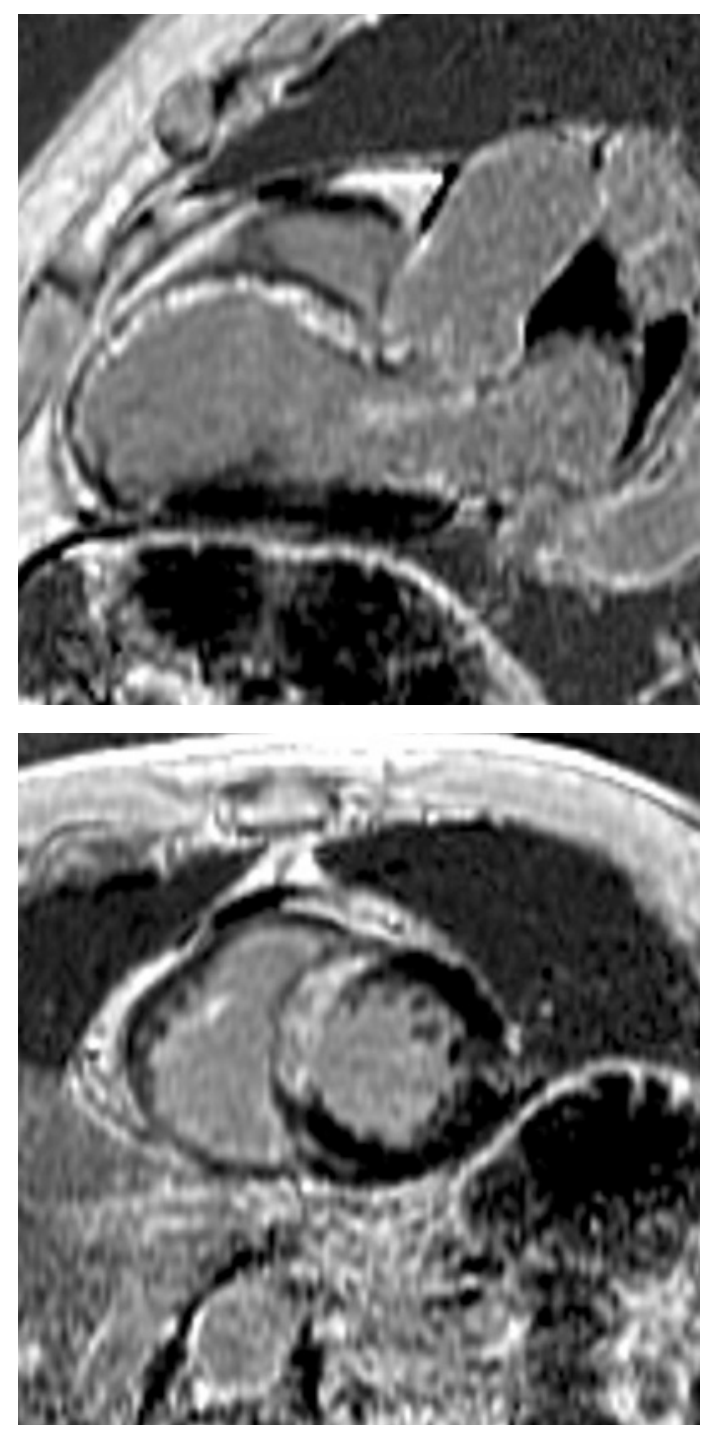

Figure 2 Delayed enhancement in a patient with a near-transmural anteroseptal myocardial infarction.

CMR is also helpful in patients with atypical chest pain. ${ }^{82}$ For example, many patients with myocarditis present with chest pain, ECG abnormalities, elevated biomarkers, but normal coronary arteries. This diagnosis is easily made with CMR. The presence of atypical mid-wall or epicardial delayed enhancement distinguishes myocarditis from MI. ${ }^{83}$ Stress CMR perfusion can detect diffuse subendocardial ischaemia in patients with syndrome $\mathrm{X}^{86}$ Acute chest pain from acute aortitis will present with irregularly thickened aortic wall and bright enhancement of the aortic wall on delayed enhancement imaging. ${ }^{878}$ CMR has been used in the diagnosis of stress cardiomyopathy (tako tsubo, left ventricular apical ballooning syndrome, and broken heart syndrome). Despite the profound left ventricular apical systolic dysfunction, there is little delayed enhancement in these patients. ${ }^{89-92}$

\section{Coronary artery imaging}

Although multidetector computed tomography (MSCT) is the most rapid and highest-resolution non-invasive technique for imaging the coronary arteries, CMR offers an alternative for imaging the coronary arteries. CMR does not require ionising radiation and can be combined with a multimodality CMR assessment of cardiac function, perfusion, and viability in a relatively short period of time. ${ }^{93}$ However, coronary imaging by CMR is still relatively complicated and many technical nuances require significant operator experience.

A few studies indicate that CMR is not as far from clinical feasibility as many physicians assume. A multicentre study of 109 patients who underwent coronary magnetic resonance angiography (MRA) reported a sensitivity of $100 \%$, a specificity of $85 \%$, and an accuracy of $87 \%$ in the detection of left main artery or three-vessel disease. ${ }^{94}$ Sakuma et al performed threedimensional whole-heart coronary MRA in 131 patients with a mean acquisition time of 12.9 (SD 4.3) minutes and a per patient sensitivity of $82 \%$, specificity of $90 \%$, and accuracy of $87 \% .{ }^{95}$ However, most experts and clinical guidelines only support the use of CMR in determining the proximal course of anomalous coronary arteries (fig 3, coronary MRA).

\section{Cardiomyopathy}

CMR can characterise cardiomyopathies in unique ways based on the magnetic properties of myocardium. ${ }^{96-99}$ Assomull et al succinctly review the use of CMR in the evaluation of congestive heart failure. ${ }^{100}$

In hypertrophic cardiomyopathy, CMR can detect patches of myocardial fibrosis with intermediate delayed enhancement. ${ }^{101-103}$ CMR can diagnose hypertrophy missed by echocardiography and more accurately determine the extent of hypertrophy. ${ }^{104}$

In patients suspected of having arrhythmogenic right ventricular dysplasia/cardiomyopathy (ARVD/C), CMR can detect global right ventricular abnormalities, right ventricular aneurysms, or regional wall motion abnormalities. Fibrofatty myocardial infiltration can be determined in patients suspected of having ARVD/C. ${ }^{105}$ Sen-Chowdhry et al have proposed modified criteria for the diagnosis of ARVD/C focusing on right ventricular size and function, right ventricular segmental dilatation, and regional right ventricular hypokinesis. These proposed criteria would improve the sensitivity in the detection of early or incompletely expressed disease. ${ }^{106}$

CMR can measure iron overload in the heart, particularly as a result of thalassaemia. ${ }^{73}{ }^{107}$ Iron overload shortens T2* relaxation properties of the myocardium and liver. Intriguingly, some patients with thalassaemia have iron overload in the heart but not in the liver and vice versa. ${ }^{73}$ Thus, CMR determinations of

Table 1 Summary of dobutamine validations

\begin{tabular}{|c|c|c|c|c|c|c|}
\hline Year & First Author & $\mathbf{N}$ & Excluded & Reference & Sensitivity & Specificity \\
\hline 2006 & Paetsch $^{77}$ & 150 & 0 & Cath $>50 \%$ & 78 & 87 \\
\hline 2006 & Jahnke $e^{75}$ & 40 & 0 & Cath $>50 \%$ & 82 & 87 \\
\hline 2004 & Paetsch $^{62}$ & 79 & & Cath $>50 \%$ & 89 & 80 \\
\hline 2004 & Wahl $^{78}$ & 170 & 10 & Cath $>50 \%$ & 89 & 84 \\
\hline 1999 & Hundley $^{74}$ & 163 & 10 & Cath $>50 \%$ & 83 & 83 \\
\hline 1999 & Nagel $^{76}$ & 208 & 36 & Cath $>50 \%$ & 86 & 86 \\
\hline
\end{tabular}


Figure 3 Whole heart coronary magnetic resonance angiography. Image provided courtesy of Vibhas Deshpande, MR Research \& Development, Siemens Medical Solutions.
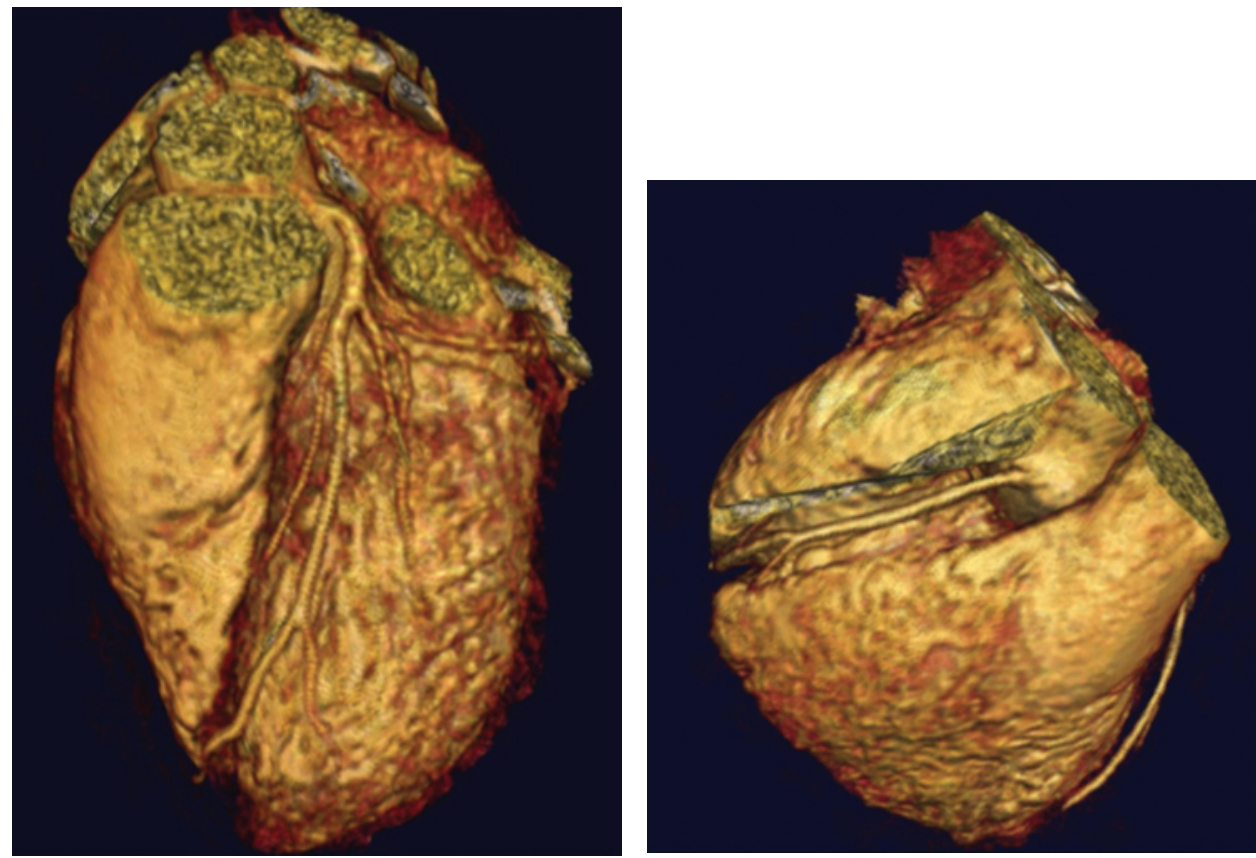

iron overload may be better at assessing patient risk than relying on liver biopsy alone and may be used to follow therapy success.

CMR is good at differentiating constrictive from restrictive cardiomyopathy due to each entity's unique presentation and physiology. Many of the infiltrative cardiomyopathies such as amyloidosis, sarcoidosis, Chagas' disease, and endomyocardial fibroelastosis have characteristic abnormalities on delayed enhancement. ${ }^{99}{ }^{108-112}$ CMR can identify thickened pericardium as well as abnormal motion of the heart in constrictive cardiomyopathy. While both CT and CMR can detect thickened pericardium, CMR is better able to distinguish between pericardial thickening and small effusion than CT ${ }^{113}$ Real-time imaging to evaluate the septum may demonstrate interventricular dependence. ${ }^{114}$ Real-time cine imaging of the inferior vena cava during respiration can also separate constrictive from restrictive physiology. ${ }^{115}$

\section{Congenital heart disease}

In a patient with congenital heart disease, anatomic connections or malformations may be identified, the direction of intracardiac shunts may be identified and quantified, and valvular anatomy and function may be assessed. Volumetric anatomic CMR depicts the complex vascular abnormalities associated with congenital syndromes and the surgical corrections. Echocardiography cannot always visualise the heart and great vessels in their entirety, particularly in adults with surgically corrected congenital heart disease. Repeated exposure to the radiation of CT is not desirable, especially in a paediatric population that is at greater risk for developing long-term radiation-related malignancies. ${ }^{116}$

CMR can provide more than simply anatomical imaging. A saturated black band technique highlights intracardiac shunting. Velocity encoded phase contrast techniques can quantify the severity of intracardiac shunts. Measuring pulmonary blood flow (Op) in the pulmonary artery and systemic blood flow (Os) in the aorta provides a noninvasive estimate of Op/Os and thus quantifies the degree of intracardiac shunting (fig 4). CMR can quantify the amount of valvular regurgitation (eg, in patients with Tetralogy of Fallot).

\section{Valvular disease}

CMR provides non-invasive clear anatomical valvular information that can impact clinical management of a patient. It is
Figure 4 Pulmonic flow (Op) and systemic flow (Qs) may be calculated non-invasively with cardiovascular magnetic resonance using simple phasecontrast techniques. This figure illustrates an abnormal Qp:OS of 1.6:1 in a patient with an atrial septal defect.

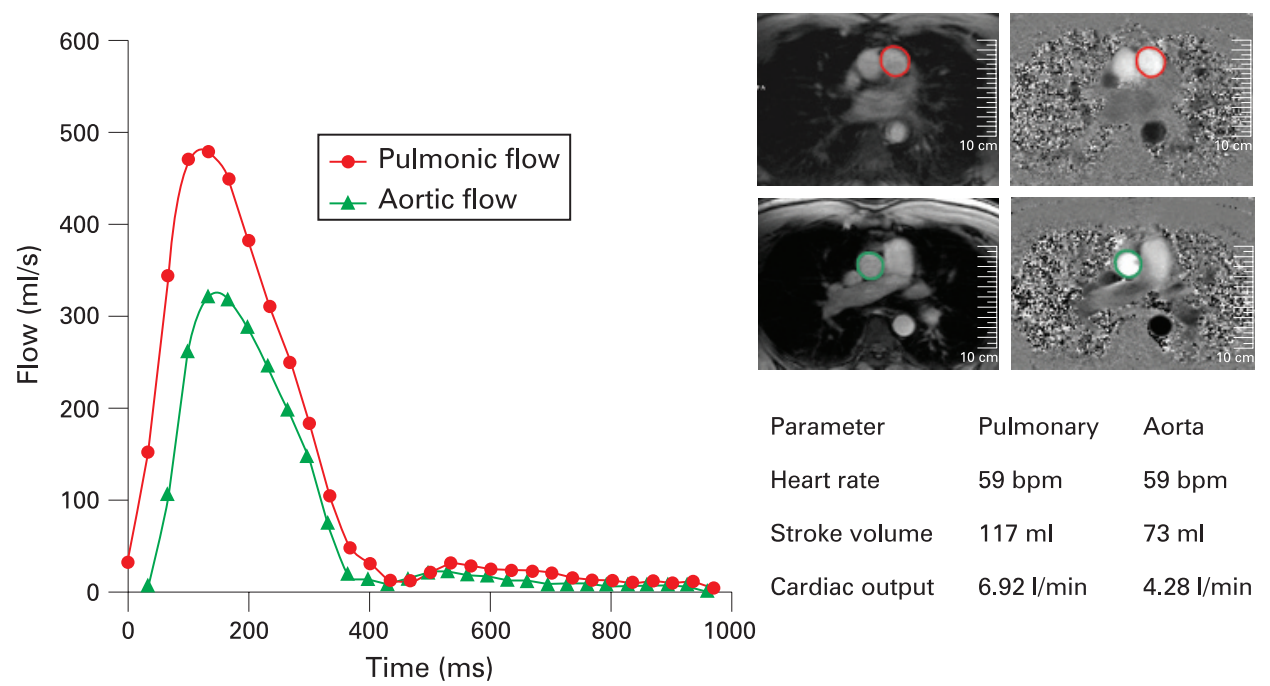




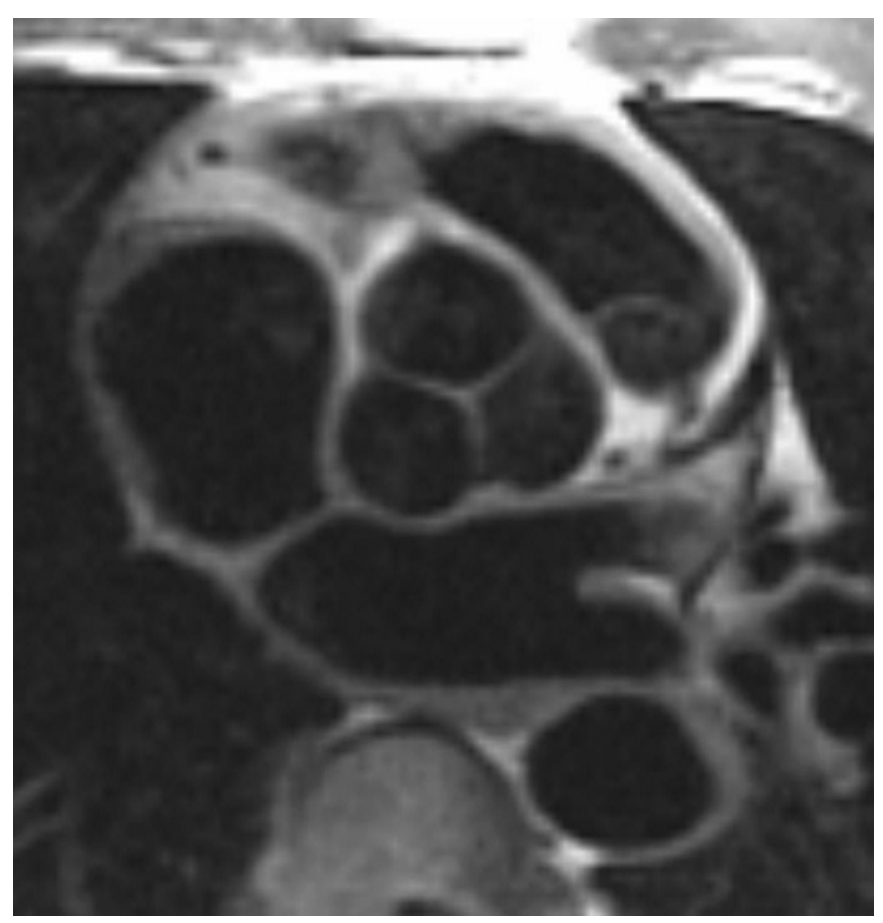

Figure 5 Black-blood fast spin echo technique to visualise the aortic valve.

possible to differentiate a bicuspid from a tricuspid aortic valve (figs 5 and 6). CMR reproducibly characterises aortic valve anatomy and the determined aortic valve area correlates well with cardiac catheterisation. ${ }^{117}$

Phase contrast techniques can reliably measure peak velocity and thus peak gradient in aortic stenosis. Valvular information in combination with accurate left ventricular volumes and assessment of thoracic aortic dilatation can assist in planning valvular replacement and, importantly, determine whether the aorta needs intervention as well. Similar data can be obtained in an assessment of the pulmonic valve, which is not always welldefined by transthoracic echocardiography.

While most valvular lesions seen by echocardiography can be assessed by CMR, echocardiography has the advantages of widespread availability and validation. CMR provides additional information in patients who have poor echocardiographic windows and is useful in patients who are poor candidates for invasive transoesophageal echocardiography or when additional surgery beyond the valve is contemplated.

\section{Assessment of cardiac masses}

Through various tissue-characterising techniques (T2-weighted, T1-weighted, first-pass perfusion, and delayed enhancement), CMR can reliably distinguish between myocardium, fat, avascular tissue (eg, thrombus), and other tissue types, such as tumours (fig 7). CMR often aids in differentiating intracardiac masses from masses that externally compress the heart.

The ability to characterise normal structures or variants makes CMR superior to echocardiography in the assessment of intracardiac mass. Atrial structures such as Eustachian valve, crista terminalis, Chiari network, and lipomatous hypertrophy are commonly mistaken by echocardiography to be a mass, and CMR can help avoid more invasive diagnostic testing. ${ }^{118}$ Contrast-enhanced CMR is twice as sensitive as echocardiography in the detection of ventricular thrombi. ${ }^{119-121}$

\section{Non-coronary vascular imaging}

Aorta and great vessels

MRI and MRA can assess large and medium-sized vascular structures. Serial exams are particularly useful in the paediatric population with congenital abnormalities of the aorta. CMR is able to visualise congenital aortic abnormalities including right-sided aortic arch, cervical aortic arch, double aortic arch, and vascular ring. As many as $42 \%$ of surgically repaired coarctations present with restenosis, dissection, pseudoaneurysm, or aneurysm at a later date. ${ }^{122-124}$

Other common indications for CMR include assessment of aortic dilation and aneurysm, aortic dissection, aortic ulcer, and intramural haematoma. While a contrast CT is the study of choice in the acutely ill, haemodynamically unstable patient, in a haemodynamically stable patient a focused CMR exam of the aorta may be performed within approximately 10-15 minutes with little cooperation from the patient (fig 8). CMR is more sensitive than CT, echocardiography, and transoesophageal echocardiography in the diagnosis of intramural haematoma. CMR can also distinguish between an acute intramural haematoma and a chronic haematoma based upon the T1 and T2 characteristics of the bleed. ${ }^{125}$
Figure 6 During diastole cine imaging, an aortic valve appears tricuspid; however, during systole, it is apparent that the valve is functionally bicuspid with fusion of the right and left cusps.
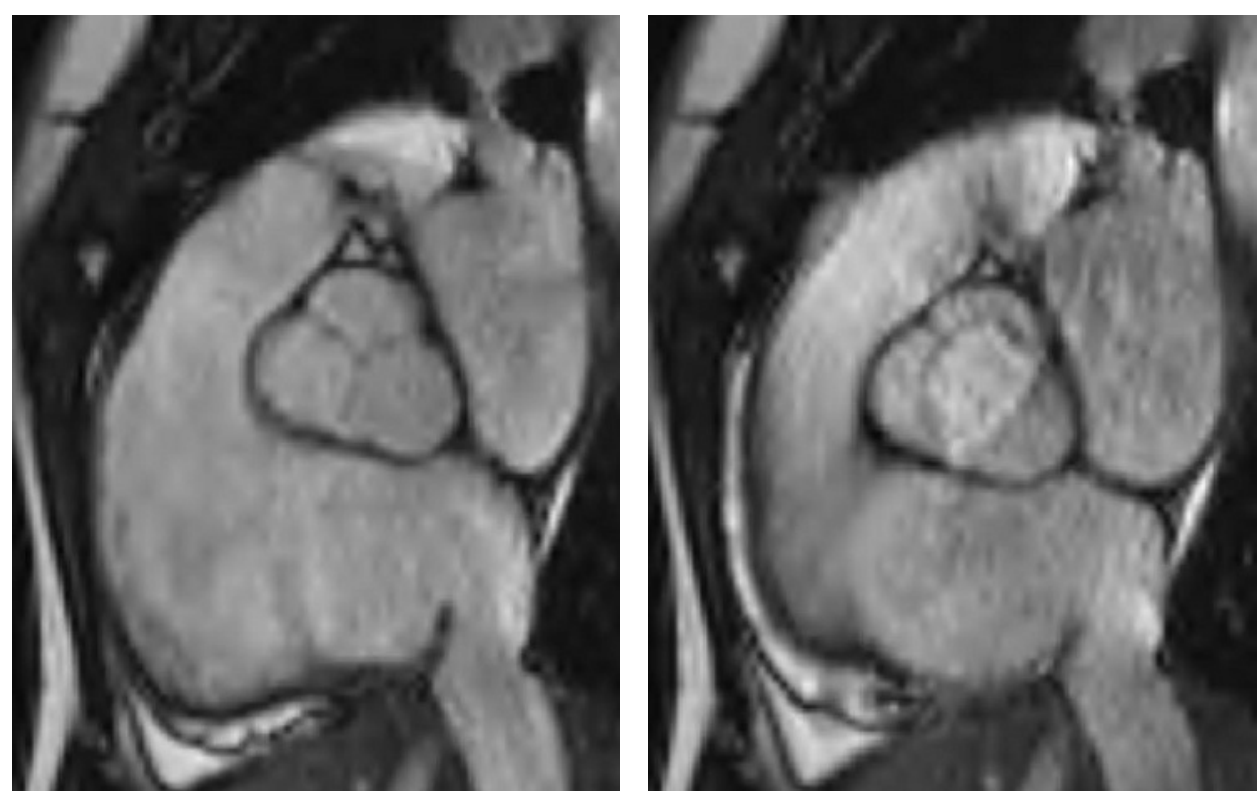
Figure 7 A 48-year-old woman presented with a markedly abnormal preoperative ECG and nuclear stress test indicating that she had an anteroseptal myocardial infarction. Cardiovascular magnetic resonance was able to demonstrate that the patient actually had an intraseptal mass (bright on the left) which was in fact a benign lipoma as demonstrated by fat saturation techniques (dark on the right after using a fat saturation technique to suppress the fat).
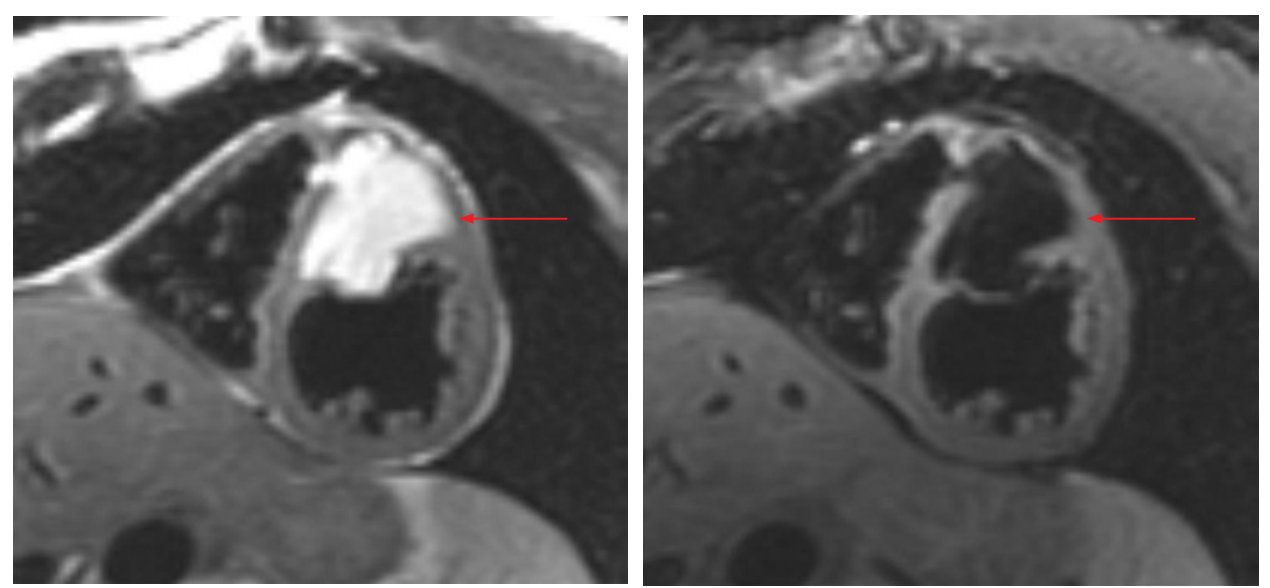

\section{Pulmonary veins}

Three-dimensional MRA can help guide electrophysiological interventions and can detect pulmonary vein stenosis after the procedure. It is possible to merge 3D MRA with fluoroscopy in the electrophysiology lab to help guide catheter tip placement and the ablation. CMR is also useful for determining the flow patterns through vessels. ${ }^{126}$

\section{FUTURE DIRECTIONS}

CMR continues to develop rapidly. Contrast agents targeted to specific tissue types are in development. For example, thrombusavid contrast agents are feasible. ${ }^{127-129}$ Lipid-specific agents have also been studied. Stem cells and macrophages have been identified with iron-based contrast agents and tracked in vivo. ${ }^{130-133}$
Interventional CMR is also a field with growing interest. A variety of percutaneous procedures used to treat vascular abnormalities and congenital heart disease are in development. ${ }^{134-137}$ Even CMR-guided percutaneous replacement of the aortic valve is feasible. ${ }^{138} \mathrm{CMR}$ can help precisely guide delivery of drugs and stem cells. ${ }^{139-141}$

\section{LIMITATIONS}

There are many factors that have slowed the dissemination of CMR. CMR is expensive and requires a skilled multidisciplinary team. In-depth CMR training is not readily available. Insufficient numbers of adequately trained physicians limit utilisation and dissemination of CMR. In many countries, reimbursement of $\mathrm{CMR}$ is not well-established. Although gadolinium-based contrast
Figure 8 This magnetic resonance angiography was performed in a Turner's Syndrome patient. Note on the anterior view the dilated size of the ascending aorta (red arrow) in comparison with the descending aorta, as well as the persistent left-sided superior vena cava (green arrow). The posterior view demonstrates the malformed aortic arch (red arrow).
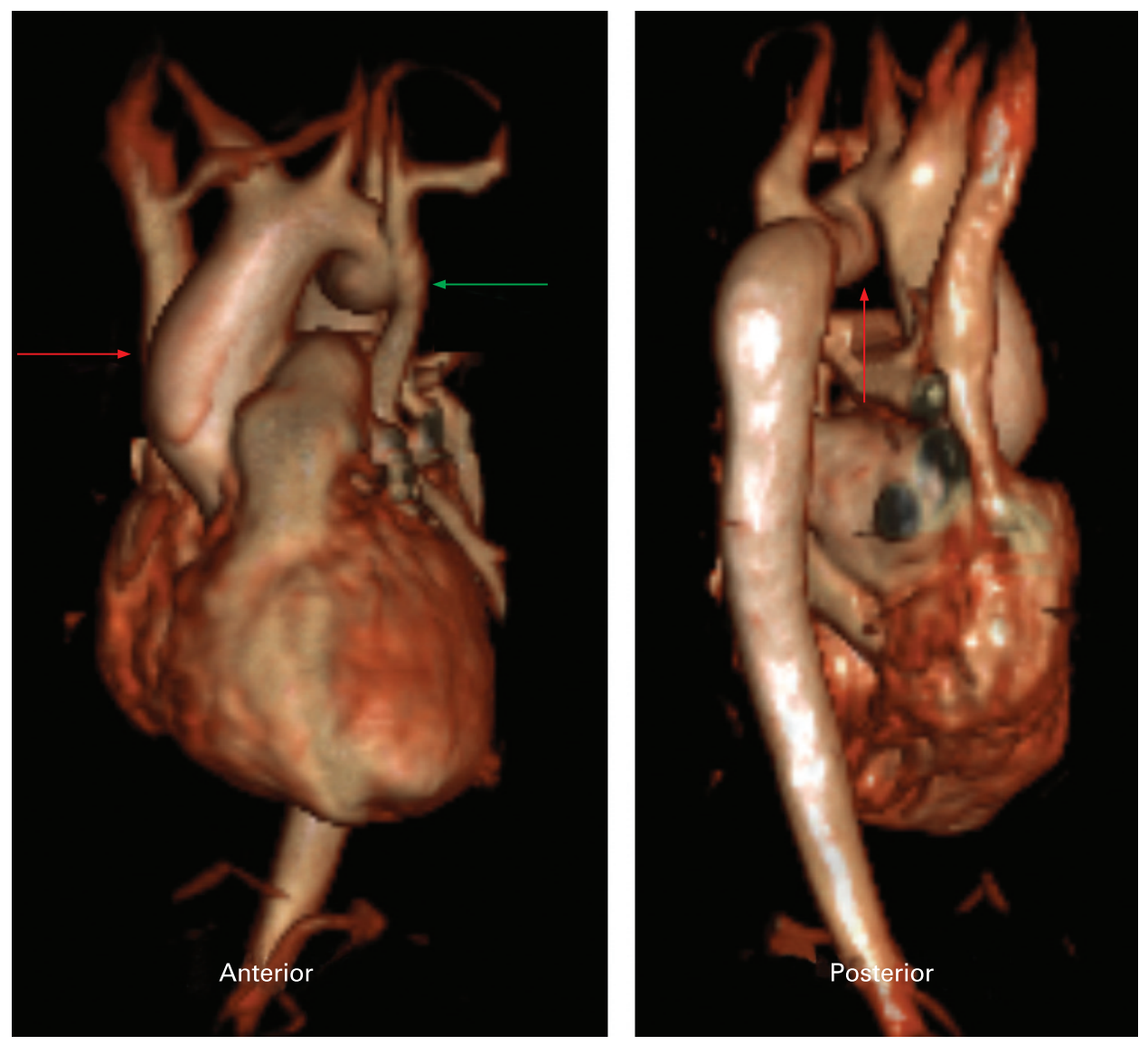
Table 2 Summary of gadolinium delayed enhancement publications

\begin{tabular}{|c|c|c|c|c|}
\hline Year & Authors & $\mathbf{n}$ & Acute vs chronic & Major findings \\
\hline 2006 & Baks $\mathrm{T}$ et $\mathrm{a}^{27}$ & 27 & $\begin{array}{l}\text { Acute } \\
\text { Chronic }\end{array}$ & Delayed enhancement predicted recovery of function. \\
\hline 2006 & Gerber BL et $a^{\beta 1}$ & $\begin{array}{l}16 \\
21\end{array}$ & $\begin{array}{l}\text { Acute } \\
\text { Chronic }\end{array}$ & Delayed enhancement correlated with MI size. \\
\hline 2005 & Baks $\mathrm{T}$ et $\mathrm{a}^{26}$ & 22 & $\begin{array}{l}\text { Acute } \\
\text { Chronic }\end{array}$ & Delayed enhancement predicted recovery of function. \\
\hline 2005 & Bello D et al. ${ }^{29}$ & 48 & Chronic & $\begin{array}{l}\text { Delayed enhancement correlated with MI size and predicted inducibility of ventricular } \\
\text { tachycardia. }\end{array}$ \\
\hline 2005 & Selvanayagam JB et a $/^{45}$ & $\begin{array}{l}50 \\
24\end{array}$ & $\begin{array}{l}\text { Acute } \\
\text { Chronic }\end{array}$ & Delayed enhancement correlated with biomarkers of necrosis. \\
\hline 2004 & Ingkanisorn WP et a ${ }^{34}$ & 33 & Acute & $\begin{array}{l}\text { Delayed enhancement predicted recovery of function and correlated with biomarkers of } \\
\text { necrosis. }\end{array}$ \\
\hline & & 20 & Chronic & \\
\hline 2004 & Lund GK et $a /^{39}$ & 60 & Acute & Delayed enhancement correlated with MI size. \\
\hline 2003 & Knuesel PR et $a l^{37}$ & 19 & Chronic & Delayed enhancement predicted recovery of function. \\
\hline 2003 & Kühl HP et al ${ }^{38}$ & 26 & Chronic & Delayed enhancement correlated with $\mathrm{Ml}$ size. \\
\hline 2003 & Wagner $\mathrm{A}$ et $\mathrm{a}^{46}$ & 91 & Chronic & Delayed enhancement correlated with MI size. \\
\hline 2002 & Gerber BL et $a^{\beta 2}$ & 20 & $\begin{array}{l}\text { Acute } \\
\text { Chronic }\end{array}$ & Delayed enhancement predicted recovery of function. \\
\hline 2002 & Klein $\mathrm{C}$ et $a^{\beta 6}$ & 31 & Chronic & Delayed enhancement correlated with $\mathrm{Ml}$ size. \\
\hline 2002 & Mahrholdt $\mathrm{H}$ et $a l^{40}$ & 20 & Chronic & Delayed enhancement correlated with MI size and was reproducible in two separate scans. \\
\hline 2002 & Perin EC et $a l^{42}$ & 15 & Chronic & $\begin{array}{l}\text { The unipolar voltage recorded during electromechanical mapping varied inversely with the } \\
\text { amount of delayed enhancement. }\end{array}$ \\
\hline 2001 & Choi KM et $a^{30}$ & 24 & Acute & $\begin{array}{l}\text { Delayed enhancement predicted recovery of function and correlated with biomarkers of } \\
\text { necrosis. }\end{array}$ \\
\hline
\end{tabular}

CKMB, muscle and brain subunits of creatine kinase; CMR, cardiovascular magnetic resonance; $\mathrm{Ml}$, myocardial infarction; $\mathrm{PCl}$, percutaneous coronary intervention.

Table 3 Summary of vasodilator perfusion CMR validation publications

\begin{tabular}{|c|c|c|c|c|c|c|c|}
\hline Year & First author & $\mathbf{n}$ & Excluded & Stress & Reference & Sensitivity & Specificity \\
\hline 2007 & Merkle et $a l^{70}$ & 228 & 0 & Adenosine & Cath $>50 \%$ & 93 & 86 \\
\hline 2006 & Ingkanisorn et $\left.a\right|^{54}$ & 141 & 4 & Adenosine & Prognosis & 100 & 93 \\
\hline 2006 & Klem et $a l^{58}$ & 92 & 3 & Adenosine & Cath $>70 \%$ & 89 & 87 \\
\hline 2006 & Pilz et $a l^{63}$ & 176 & 5 & Adenosine & Cath $>70 \%$ & 96 & 83 \\
\hline 2006 & Rieber et $a l^{66}$ & 50 & 7 & Adenosine & Cath $>50 \%$ and FFR & 88 & 90 \\
\hline 2005 & Okuda et $a l^{60}$ & 33 & 0 & Dipyridamole & Cath $>70 \%$ & 84 & 87 \\
\hline 2005 & Plein et $a l^{65}$ & 92 & & Adenosine & Cath $>70 \%$ & 88 & 82 \\
\hline 2005 & Sakuma et $a l^{67}$ & 40 & 0 & Dipyridamole & Cath $>70 \%$ & 81 & 68 \\
\hline 2004 & Bunce et $\left.a\right|^{50}$ & 35 & 0 & Adenosine & Cath $>50 \%$ & 74 & 71 \\
\hline 2004 & Giang et $a l^{52}$ & 94 & 14 & Adenosine & Cath $>50 \%$ & 93 & 75 \\
\hline 2004 & Kawase et $a l^{56}$ & 50 & 0 & Nicorandil & Cath $>70 \%$ & 94 & 94 \\
\hline 2004 & Paetsch et $a l^{61}$ & 49 & 0 & Adenosine & Cath $>75 \%$ & 89 & 80 \\
\hline 2004 & Paetsch et $a l^{62}$ & 79 & & Adenosine & $\mathrm{QCA}>50 \%$ & 91 & 62 \\
\hline 2004 & Plein et $a l^{64}$ & 72 & 4 & Adenosine & Cath $>70 \%$ & 88 & 83 \\
\hline 2004 & Takase et $a l^{69}$ & 102 & 0 & Dipyridamole & Cath $>50 \%$ & 93 & 85 \\
\hline 2003 & Doyle et $a^{51}$ & 199 & 15 & Dipyridamole & Cath $>70 \%$ & 78 & 82 \\
\hline 2003 & $\mid$ shida et $\left.a\right|^{55}$ & 104 & 0 & Dipyridamole & Cath $>70 \%$ & 84 & 82 \\
\hline 2003 & Kinoshita et $a l^{57}$ & 27 & & Dipyridamole & Cath $>75 \%$ & 55 & 77 \\
\hline 2003 & Nagel et $\left.a\right|^{59}$ & 90 & 6 & Adenosine & Cath $>75 \%$ & 88 & 90 \\
\hline 2002 & Ibrahim et $\left.a\right|^{53}$ & 25 & & Adenosine & $\mathrm{QCA}>75 \%$ & 69 & 89 \\
\hline 2001 & Schwitter et $a l^{68}$ & 48 & 1 & Dipyridamole & $\mathrm{QCA}>50 \%$ & 85 & 94 \\
\hline 2000 & Al-Saadi et $a l^{49}$ & 40 & 6 & Dipyridamole & Cath $>75 \%$ & 90 & 83 \\
\hline
\end{tabular}

CMR, cardiovascular magnetic resonance. 


\section{Box 1 Appropriate indications for the use of CMR ${ }^{142 *}$}

Detection of CAD: Symptomatic - evaluation of chest pain syndrome (use of vasodilator perfusion CMR or dobutamine stress function CMR)

- Intermediate pre-test probability of CAD

- ECG uninterpretable OR unable to exercise

Detection of CAD: Symptomatic - evaluation of intracardiac structures (use of MR coronary angiography)

- Evaluation of suspected coronary anomalies

Risk assessment with prior test results (use of vasodilator perfusion CMR or dobutamine stress function CMR)

- Coronary angiography (catheterisation or CT)

- Stenosis of unclear significance

Structure and Function — evaluation of ventricular and valvular function

Procedures may include LV/RV mass and volumes, MR angiography, quantification of valvular disease, and delayed contrast enhancement

- Assessment of complex congenital heart disease including anomalies of coronary circulation, great vessels, and cardiac chambers and valves

- Procedures may include LV/RV mass and volumes, MR angiography, quantification of valvular disease, and contrast enhancement

- Evaluation of LV function following myocardial infarction OR in heart failure patients

- Patients with technically limited images from echocardiogram

- Quantification of LV function

- Discordant information that is clinically significant from prior tests

- Evaluation of specific cardiomyopathies (infiltrative (amyloid, sarcoid), HCM, or due to cardiotoxic therapies)

- Use of delayed enhancement

- Characterisation of native and prosthetic cardiac valves-including planimetry of stenotic disease and quantification of regurgitant disease

- Patients with technically limited images from echocardiogram or TEE

- Evaluation for arrhythmogenic right ventricular cardiomyopathy (ARVC)

- Patients presenting with syncope or ventricular arrhythmia

- Evaluation of myocarditis or myocardial infarction with normal coronary arteries

- Positive cardiac enzymes without obstructive atherosclerosis on angiography

Structure and Function-evaluation of intracardiac and extracardiac structures

- Evaluation of cardiac mass (suspected tumour or thrombus)

- Use of contrast for perfusion and enhancement

- Evaluation of pericardial conditions (pericardial mass, constrictive pericarditis)

- Evaluation for aortic dissection

- Evaluation of pulmonary veins prior to radiofrequency ablation for atrial fibrillation

- Left atrial and pulmonary venous anatomy including dimensions of veins for mapping purposes

Detection of myocardial scar and viability - evaluation of myocardial scar (use of late gadolinium enhancement)

- To determine the location and extent of myocardial necrosis including "no reflow" regions

- Post acute myocardial infarction

- To determine viability prior to revascularisation

- Establish likelihood of recovery of function with revascularisation (PCI or CABG) or medical therapy

- To determine viability prior to revascularisation

- Viability assessment by SPECT or dobutamine echo has provided "equivocal or indeterminate" results

*adapted from ACCF/ACR/SCCT/SCMR/ASNC/NASCI/SCAI/SIR 2006 appropriateness criteria for cardiac computed tomography and cardiac magnetic resonance imaging. J Am Coll Cardiol 2006;48:1475-97.

agents are in everyday clinical use worldwide, cardiovascular applications are not yet approved by the United States Food and Drug Administration. Currently it is easier to run an MRI for profit by doing non-cardiac applications. Thus, significant economic issues must be addressed.

MRI scanners trigger claustrophobia in many patients. Other patients cannot undergo MRI scans due to implanted devices like pacemakers or defibrillators. Arrhythmias and respiratory insufficiency compromise many of the highest quality CMR methods. Technology development can solve most of these issues.

\section{CONCLUSION}

With advances in CMR technology, multiple clinical indications have followed. Although there is overlap with other cardiac imaging modalities, CMR often works in a complementary fashion to these other techniques or resolves residual diagnostic dilemmas. The strengths of CMR lie in its ability to comprehensively image cardiac anatomy, function, perfusion, viability and physiology, and put this information in the context of the wide field of view of surrounding vascular and non-cardiac anatomy. At a time when serious concerns are being raised about the medical use of ionising radiation, it is reassuring to know that CMR provides high-quality diagnostic information without a need for radiation.

Competing interests: None.

\section{REFERENCES}

1. Sodickson DK, McKenzie CA, Ohliger MA, et al. Recent advances in image reconstruction, coil sensitivity calibration, and coil array design for SMASH and generalized parallel MRI. Magma 2002;13:158-63.

2. Sodickson DK, Manning WJ. Simultaneous acquisition of spatial harmonics (SMASH): fast imaging with radiofrequency coil arrays. Magn Reson Med 1997; 38:591-603.

3. Pruessmann KP, Weiger M, Scheidegger MB, et al. SENSE: sensitivity encoding for fast MRI. Magn Reson Med 1999;42:952-62.

4. Levine GN, Gomes AS, Arai AE, et al. Safety of magnetic resonance imaging in patients with cardiovascular devices: an American Heart Association scientific statement from the Committee on Diagnostic and Interventional Cardiac Catheterization, Council on Clinical Cardiology, and the Council on Cardiovascular Radiology and Intervention: endorsed by the American College of Cardiology 
Foundation, the North American Society for Cardiac Imaging, and the Society for Cardiovascular Magnetic Resonance. Circulation 2007;116:2878-91.

5. Shellock R \& D Services, Inc. and Frank G. Shellock, Ph.D. MRI Safety (INSTITUTE FOR MAGNETIC RESONANCE SAFETY, EDUCATION, AND RESEARCH Website). 20012007. Available at http://www.imrser.org and http://www.mrisafety.com.

6. Kanal E, Borgstede JP, Barkovich AJ, et al. American College of Radiology White Paper on MR Safety: 2004 update and revisions. AJR Am J Roentgenol 2004;182:1111-4.

7. Shellock FG. Biological effects and safety aspects of magnetic resonance imaging. Magn Reson 0 1989:5:243-61.

8. Shellock FG, Shellock VJ. Metallic stents: evaluation of MR imaging safety. AJR Am J Roentgenol 1999;173:543-7.

9. Shellock F. Reference Manual for Magnetic Resonance Safety, Implants, and Devices. Los Angeles: Biomedical Research Publishing Group, 2007.

10. Caputo GR, Tscholakoff D, Sechtem U, et al. Measurement of canine left ventricular mass by using MR imaging. AJR Am J Roentgenol 1987;148:33-8.

11. Koch JA, Poll LW, Godehardt E, et al. Right and left ventricular volume measurements in an animal heart model in vitro: first experiences with cardiac MRI at 1.0 T. Eur Radiol 2000;10:455-8.

12. Nahrendorf $\mathbf{M}$, Hiller $\mathrm{KH}$, Hu K, et al. Cardiac magnetic resonance imaging in small animal models of human heart failure. Med Image Anal 2003;7:369-75.

13. Pattynama PM, Lamb HJ, van der Velde EA, et al. Left ventricular measurements with cine and spin-echo MR imaging: a study of reproducibility with variance component analysis. Radiology 1993;187:261-8.

14. Rehr RB, Malloy CR, Filipchuk NG, et al. Left ventricular volumes measured by MR imaging. Radiology 1985;156:717-9.

15. Semelka RC, Tomei E, Wagner S, et al. Interstudy reproducibility of dimensional and functional measurements between cine magnetic resonance studies in the morphologically abnormal left ventricle. Am Heart J 1990;119:1367-73.

16. Semelka RC, Tomei E, Wagner S, et al. Normal left ventricular dimensions and function: interstudy reproducibility of measurements with cine MR imaging. Radiology 1990;174:763-8.

17. Shapiro EP, Rogers WJ, Beyar R, et al. Determination of left ventricular mass by magnetic resonance imaging in hearts deformed by acute infarction. Circulation 1989;79:706-11.

18. Stratemeier EJ, Thompson R, Brady TJ, et al. Ejection fraction determination by MR imaging: comparison with left ventricular angiography. Radiology 1986:158:775-7.

19. Park J, Metaxas D, Axel L. Analysis of left ventricular wall motion based on volumetric deformable models and MRI-SPAMM. Med Image Anal 1996;1:53-71.

20. Aletras AH, Balaban RS, Wen H. High-resolution strain analysis of the human heart with fast-DENSE. J Magn Reson 1999;140:41-57.

21. Aletras AH, Ding S, Balaban RS, et al. DENSE: displacement encoding with stimulated echoes in cardiac functional MRI. J Magn Reson 1999;137:247-52.

22. Osman NF, Kerwin WS, McVeigh ER, et al. Cardiac motion tracking using CINE harmonic phase (HARP) magnetic resonance imaging. Magn Reson Med 1999;42:1048-60.

23. Fogel MA, Wilson RD, Flake $A$, et al. Preliminary investigations into a new method of functional assessment of the fetal heart using a novel application of 'real-time' cardiac magnetic resonance imaging. Fetal Diagn Ther 2005;20:475-80.

24. Simonetti OP, Kim RJ, Fieno DS, et al. An improved MR imaging technique for the visualization of myocardial infarction. Radiology 2001;218:215-23.

25. Kim RJ, Fieno DS, Parrish TB, et al. Relationship of MRI delayed contrast enhancement to irreversible injury, infarct age, and contractile function. Circulation 1999;100:1992-2002.

26. Baks T, van Geuns RJ, Biagini E, et al. Recovery of left ventricular function after primary angioplasty for acute myocardial infarction. Eur Heart J 2005;26:1070-7.

27. Baks T, van Geuns RJ, Duncker DJ, et al. Prediction of left ventricular function after drug-eluting stent implantation for chronic total coronary occlusions. J Am Coll Cardiol 2006; 47:721-5.

28. Beek AM, Kuhl HP, Bondarenko 0, et al. Delayed contrast-enhanced magnetic resonance imaging for the prediction of regional functional improvement after acute myocardial infarction. J Am Coll Cardiol 2003;42:895-901.

29. Bello D, Fieno DS, Kim RJ, et al. Infarct morphology identifies patients with substrate for sustained ventricular tachycardia. J Am Coll Cardiol 2005;45:1104-8.

30. Choi KM, Kim RJ, Gubernikoff G, et al. Transmural extent of acute myocardial infarction predicts long-term improvement in contractile function. Circulation 2001;104:1101-7.

31. Gerber BL, Belge B, Legros GJ, et al. Characterization of acute and chronic myocardial infarcts by multidetector computed tomography: comparison with contrast-enhanced magnetic resonance. Circulation 2006;113:823-33.

32. Gerber BL, Garot J, Bluemke DA, et al. Accuracy of contrast-enhanced magnetic resonance imaging in predicting improvement of regional myocardial function in patients after acute myocardial infarction. Circulation 2002;106:1083-9.

33. Ibrahim T, Nekolla SG, Hornke M, et al. Quantitative measurement of infarct size by contrast-enhanced magnetic resonance imaging early after acute myocardial infarction: comparison with single-photon emission tomography using Tc99msestamibi. J Am Coll Cardiol 2005;45:544-52.

34. Ingkanisorn WP, Rhoads KL, Aletras AH, et al. Gadolinium delayed enhancement cardiovascular magnetic resonance correlates with clinical measures of myocardial infarction. J Am Coll Cardiol 2004;43:2253-9.

35. Kim RJ, Wu E, Rafael A, et al. The use of contrast-enhanced magnetic resonance imaging to identify reversible myocardial dysfunction. N Engl J Med 2000;343:1445-53.

36. Klein C, Nekolla SG, Bengel FM, et al. Assessment of myocardial viability with contrast-enhanced magnetic resonance imaging: comparison with positron emission tomography. Circulation 2002;105:162-7.
37. Knuesel PR, Nanz D, Wyss C, et al. Characterization of dysfunctional myocardium by positron emission tomography and magnetic resonance: relation to functional outcome after revascularization. Circulation 2003;108:1095-100.

38. Kuhl HP, Beek AM, van der Weerdt AP, et al. Myocardial viability in chronic ischemic heart disease: comparison of contrast-enhanced magnetic resonance imaging with (18)F-fluorodeoxyglucose positron emission tomography. J Am Coll Cardiol 2003:41:1341-8.

39. Lund GK, Stork A, Saeed M, et al. Acute myocardial infarction: evaluation with firstpass enhancement and delayed enhancement MR imaging compared with 201TI SPECT imaging. Radiology 2004;232:49-57.

40. Mahrholdt $\mathbf{H}$, Wagner A, Holly TA, et al. Reproducibility of chronic infarct size measurement by contrast-enhanced magnetic resonance imaging. Circulation 2002; 106:2322-7.

41. Nelson C, McCrohon J, Khafagi F, et al. Impact of scar thickness on the assessment of viability using dobutamine echocardiography and thallium singlephoton emission computed tomography: a comparison with contrast-enhanced magnetic resonance imaging. J Am Coll Cardiol 2004;43:1248-56.

42. Perin EC, Silva GV, Sarmento-Leite R, et al. Assessing myocardial viability and infarct transmurality with left ventricular electromechanical mapping in patients with stable coronary artery disease: validation by delayed-enhancement magnetic resonance imaging. Circulation 2002;106:957-61.

43. Ricciardi MJ, Wu E, Davidson CJ, et al. Visualization of discrete microinfarction after percutaneous coronary intervention associated with mild creatine kinase-MB elevation. Circulation 2001;103:2780-3

44. Selvanayagam JB, Kardos A, Francis JM, et al. Value of delayed-enhancement cardiovascular magnetic resonance imaging in predicting myocardial viability after surgical revascularization. Circulation 2004;110:1535-41.

45. Selvanayagam JB, Porto I, Channon $\mathrm{K}$, et al. Troponin elevation after percutaneous coronary intervention directly represents the extent of irreversible myocardial injury: insights from cardiovascular magnetic resonance imaging. Circulation 2005;111:1027-32.

46. Wagner A, Mahrholdt H, Holly TA, et al. Contrast-enhanced MRI and routine single photon emission computed tomography (SPECT) perfusion imaging for detection of subendocardial myocardial infarcts: an imaging study. Lancet 2003;361:374-9.

47. Wellnhofer E, Olariu A, Klein C, et al. Magnetic resonance low-dose dobutamine test is superior to SCAR quantification for the prediction of functional recovery. Circulation 2004;109:2172-4.

48. Wu E, Judd RM, Vargas JD, et al. Visualisation of presence, location, and transmura extent of healed Q-wave and non-Q-wave myocardial infarction. Lancet 2001;357:21-8.

49. Al-Saadi N, Nagel E, Gross M, et al. Noninvasive detection of myocardial ischemia from perfusion reserve based on cardiovascular magnetic resonance. Circulation 2000;101:1379-83.

50. Bunce NH, Reyes E, Keegan J, et al. Combined coronary and perfusion cardiovascular magnetic resonance for the assessment of coronary artery stenosis. J Cardiovasc Magn Reson 2004;6:527-39.

51. Doyle M, Fuisz A, Kortright E, et al. The impact of myocardial flow reserve on the detection of coronary artery disease by perfusion imaging methods: an NHLBI WISE study. J Cardiovasc Magn Reson 2003:5:475-85.

52. Giang TH, Nanz D, Coulden R, et al. Detection of coronary artery disease by magnetic resonance myocardial perfusion imaging with various contrast medium doses: first European multi-centre experience. Eur Heart J 2004;25:1657-65.

53. Ibrahim T, Nekolla SG, Schreiber K, et al. Assessment of coronary flow reserve: comparison between contrast-enhanced magnetic resonance imaging and positron emission tomography. J Am Coll Cardiol 2002;39:864-70.

54. Ingkanisorn WP, Kwong RY, Bohme NS, et al. Prognosis of negative adenosine stress magnetic resonance in patients presenting to an emergency department with chest pain. J Am Coll Cardiol 2006; 47:1427-32.

55. Ishida N, Sakuma H, Motoyasu M, et al. Noninfarcted myocardium: correlation between dynamic first-pass contrast-enhanced myocardial MR imaging and quantitative coronary angiography. Radiology 2003;229:209-16.

56. Kawase $\mathbf{Y}$, Nishimoto M, Hato K, et al. Assessment of coronary artery disease with nicorandil stress magnetic resonance imaging. Osaka City Med J 2004:50:87-94.

57. Kinoshita M, Nomura M, Harada M, et al. Myocardial perfusion magnetic resonance imaging for diagnosing coronary arterial stenosis. Jpn Heart J 2003:44:323-34.

58. Klem I, Heitner JF, Shah DJ, et al. Improved detection of coronary artery disease by stress perfusion cardiovascular magnetic resonance with the use of delayed enhancement infarction imaging. J Am Coll Cardiol 2006;47:1630-8.

59. Nagel E, Klein C, Paetsch I, et al. Magnetic resonance perfusion measurements for the noninvasive detection of coronary artery disease. Circulation 2003;108:432-7.

60. Okuda S, Tanimoto A, Satoh T, et al. Evaluation of ischemic heart disease on a 1.5 Tesla scanner: combined first-pass perfusion and viability study. Radiat Med 2005;23:230-5.

61. Paetsch I, Foll D, Langreck $\mathrm{H}$, et al. Myocardial perfusion imaging using OMNISCAN: a dose finding study for visual assessment of stress-induced regional perfusion abnormalities. J Cardiovasc Magn Reson 2004;6:803-9.

62. Paetsch I, Jahnke C, Wahl A, et al. Comparison of dobutamine stress magnetic resonance, adenosine stress magnetic resonance, and adenosine stress magnetic resonance perfusion. Circulation 2004;110:835-42.

63. Pilz G, Bernhardt $\mathrm{P}$, Klos M, et al. Clinical implication of adenosine-stress cardiac magnetic resonance imaging as potential gatekeeper prior to invasive examination in patients with AHA/ACC class II indication for coronary angiography. Clin Res Cardiol 2006:95:531-8.

64. Plein S, Greenwood JP, Ridgway JP, et al. Assessment of non-ST-segment elevation acute coronary syndromes with cardiac magnetic resonance imaging. $J$ Am Coll Cardiol 2004:44:2173-81 
65. Plein S, Radjenovic A, Ridgway JP, et al. Coronary artery disease: myocardial perfusion MR imaging with sensitivity encoding versus conventional angiography. Radiology 2005;235:423-30

66. Rieber J, Huber A, Erhard I, et al. Cardiac magnetic resonance perfusion imaging for the functional assessment of coronary artery disease: a comparison with coronary angiography and fractional flow reserve. Eur Heart J 2006;27:1465-71.

67. Sakuma H, Suzawa N, Ichikawa Y, et al. Diagnostic accuracy of stress first-pass contrast-enhanced myocardial perfusion MRI compared with stress myocardial perfusion scintigraphy. AJR Am J Roentgenol 2005;185:95-102.

68. Schwitter J, Nanz D, Kneifel S, et al. Assessment of myocardial perfusion in coronary artery disease by magnetic resonance: a comparison with positron emission tomography and coronary angiography. Circulation 2001;103:2230-5.

69. Takase B, Nagata M, Kihara T, et al. Whole-heart dipyridamole stress first-pass myocardial perfusion MRI for the detection of coronary artery disease. Jpn Heart J 2004; 45:475-86.

70. Merkle N, Wohrle J, Grebe 0, et al. Assessment of myocardial perfusion for detection of coronary artery stenoses by steady-state, free-precession magnetic resonance first-pass imaging. Heart 2007;93:1381-5.

71. Pennell DJ, Underwood SR, Manzara CC, et al. Magnetic resonance imaging during dobutamine stress in coronary artery disease. Am J Cardiol 1992;70:34-40.

72. Wahl A, Paetsch I, Gollesch A, et al. Safety and feasibility of high-dose dobutamineatropine stress cardiovascular magnetic resonance for diagnosis of myocardial ischaemia: experience in 1000 consecutive cases. Eur Heart J 2004;25:1230-6.

73. Anderson LJ, Holden S, Davis B, et al. Cardiovascular T2-star (T2*) magnetic resonance for the early diagnosis of myocardial iron overload. Eur Heart J 2001;22:2171-9.

74. Hundley WG, Hamilton CA, Thomas MS, et al. Utility of fast cine magnetic resonance imaging and display for the detection of myocardial ischemia in patients not well suited for second harmonic stress echocardiography. Circulation 1999;100:1697-702.

75. Jahnke C, Paetsch I, Gebker R, et al. Accelerated 4D dobutamine stress MR imaging with k-t BLAST: feasibility and diagnostic performance. Radiology 2006;241:718-28.

76. Nagel E, Lehmkuhl HB, Bocksch W, et al. Noninvasive diagnosis of ischemia-induced wall motion abnormalities with the use of high-dose dobutamine stress MRI: comparison with dobutamine stress echocardiography. Circulation 1999;99:763-70.

77. Paetsch I, Jahnke C, Ferrari VA, et al. Determination of interobserver variability for identifying inducible left ventricular wall motion abnormalities during dobutamine stress magnetic resonance imaging. Eur Heart J 2006;27:1459-64.

78. Wahl A, Paetsch I, Roethemeyer S, et al. High-dose dobutamine-atropine stress cardiovascular MR imaging after coronary revascularization in patients with wall motion abnormalities at rest. Radiology 2004:233:210-6.

79. Sharkey SW, Lesser JR, Zenovich AG, et al. Acute and reversible cardiomyopathy provoked by stress in women from the United States. Circulation 2005;111:472-9.

80. Teraoka K, Kiuchi S, Takada N, et al. Images in cardiovascular medicine. No delayed enhancement on contrast magnetic resonance imaging with Takotsubo cardiomyopathy. Circulation 2005;111:e261-2.

81. Hundley WG, Morgan TM, Neagle CM, et al. Magnetic resonance imaging determination of cardiac prognosis. Circulation 2002;106:2328-33.

82. Jahnke C, Nagel E, Gebker $\mathrm{R}$, et al. Prognostic value of cardiac magnetic resonance stress tests: adenosine stress perfusion and dobutamine stress wall motion imaging. Circulation 2007;115:1769-76.

83. Kwong RY, Schussheim AE, Rekhraj S, et al. Detecting acute coronary syndrome in the emergency department with cardiac magnetic resonance imaging. Circulation 2003; 107:531-7.

84. Arai AE. False positive or true positive troponin in patients presenting with chest pain but 'normal' coronary arteries: lessons from cardiac MRI. Eur Heart J 2007;28:1175-7.

85. Friedrich MG, Strohm 0, Schulz-Menger J, et al. Contrast media-enhanced magnetic resonance imaging visualizes myocardial changes in the course of viral myocarditis. Circulation 1998;97:1802-9.

86. Ingkanisorn WP, Paterson DI, Calvo KR, et al. Cardiac magnetic resonance appearance of myocarditis caused by high dose IL-2: similarities to communityacquired myocarditis. J Cardiovasc Magn Reson 2006;8:353-60.

87. Mahrholdt H, Goedecke C, Wagner A, et al. Cardiovascular magnetic resonance assessment of human myocarditis: a comparison to histology and molecular pathology. Circulation 2004;109:1250-8

88. Panting JR, Gatehouse PD, Yang GZ, et al. Abnormal subendocardial perfusion in cardiac syndrome $\mathrm{X}$ detected by cardiovascular magnetic resonance imaging. N Engl J Med 2002;346:1948-53.

89. Choe YH, Kim DK, Koh EM, et al. Takayasu arteritis: diagnosis with MR imaging and MR angiography in acute and chronic active stages. J Magn Reson Imaging 1999;10:751-7.

90. Narvaez J, Narvaez JA, Nolla JM, et al. Giant cell arteritis and polymyalgia rheumatica: usefulness of vascular magnetic resonance imaging studies in the diagnosis of aortitis. Rheumatology (Oxford) 2005;44:479-83.

91. Nef HM, Mollmann H, Hamm CW, et al. [Tako-Tsubo cardiomyopathy--a nove cardiac entity?]. Herz 2006;31:473-9.

92. Wittstein IS, Thiemann DR, Lima JA, et al. Neurohumoral features of myocardial stunning due to sudden emotional stress. N Engl J Med 2005;352:539-48.

93. Plein S, Ridgway JP, Jones TR, et al. Coronary artery disease: assessment with a comprehensive MR imaging protocol--initial results. Radiology 2002;225:300-7.

94. Kim WY, Danias PG, Stuber M, et al. Coronary magnetic resonance angiography for the detection of coronary stenoses. N Engl J Med 2001;345:1863-9.

95. Sakuma H, Ichikawa $Y$, Chino $\mathrm{S}$, et al. Detection of coronary artery stenosis with wholeheart coronary magnetic resonance angiography. J Am Coll Cardiol 2006;48:1946-50.

96. Assomull RG, Prasad SK, Lyne J, et al. Cardiovascular magnetic resonance, fibrosis, and prognosis in dilated cardiomyopathy. J Am Coll Cardiol 2006:48:1977-85.
97. Maceira AM, Joshi J, Prasad SK, et al. Cardiovascular magnetic resonance in cardiac amyloidosis. Circulation 2005;111:186-93.

98. O'Hanlon R, Assomull RG, Prasad SK. Use of cardiovascular magnetic resonance for diagnosis and management in hypertrophic cardiomyopathy. Curr Cardiol Rep 2007:9:51-6.

99. Smedema JP, Snoep G, van Kroonenburgh MP, et al. The additional value of gadolinium-enhanced MRI to standard assessment for cardiac involvement in patients with pulmonary sarcoidosis. Chest 2005;128:1629-37.

100. Assomull RG, Pennell DJ. Prasad SK. Cardiovascular magnetic resonance in the evaluation of heart failure. Heart 2007;93:985-92.

101. Moon JC, McKenna WJ, McCrohon JA, et al. Toward clinical risk assessment in hypertrophic cardiomyopathy with gadolinium cardiovascular magnetic resonance. J Am Coll Cardiol 2003;41:1561-7.

102. Moon JC, Mogensen J, Elliott PM, et al. Myocardial late gadolinium enhancement cardiovascular magnetic resonance in hypertrophic cardiomyopathy caused by mutations in troponin I. Heart 2005;91:1036-40.

103. Moon JC, Reed E, Sheppard MN, et al. The histologic basis of late gadolinium enhancement cardiovascular magnetic resonance in hypertrophic cardiomyopathy. J Am Coll Cardiol 2004;43:2260-4.

104. Rickers C, Wilke NM, Jerosch-Herold M, et al. Utility of cardiac magnetic resonance imaging in the diagnosis of hypertrophic cardiomyopathy. Circulation 2005;112:855-61.

105. Tandri H, Saranathan M, Rodriguez ER, et al. Noninvasive detection of myocardial fibrosis in arrhythmogenic right ventricular cardiomyopathy using delayed enhancement magnetic resonance imaging. J Am Coll Cardiol 2005:45:98-103

106. Sen-Chowdhry S, Prasad SK, Syrris P, et al. Cardiovascular magnetic resonance in arrhythmogenic right ventricular cardiomyopathy revisited: comparison with task force criteria and genotype. J Am Coll Cardiol 2006:48:2132-40.

107. Anderson LJ, Westwood MA, Holden S, et al. Myocardial iron clearance during reversal of siderotic cardiomyopathy with intravenous desferrioxamine: a prospective study using T2* cardiovascular magnetic resonance. Br J Haematol 2004:127:348-55.

108. Rochitte CE, Oliveira PF, Andrade JM, et al. Myocardial delayed enhancement by magnetic resonance imaging in patients with Chagas' disease: a marker of disease severity. J Am Coll Cardiol 2005:46:1553-8.

109. Smedema JP, Truter R, de Klerk PA, et al. Cardiac sarcoidosis evaluated with gadolinium-enhanced magnetic resonance and contrast-enhanced 64-slice computed tomography. Int J Cardiol 2006;112:261-3.

110. Bertini PJ, Parga JR, Chagas AC, et al. Compensatory enlargement of human coronary arteries identified by magnetic resonance imaging. Braz J Med Biol Res 2005;38:661-7.

111. Rochitte CE, Nacif MS, de Oliveira Junior AC, et al. Cardiac magnetic resonance in Chagas' disease. Artif Organs 2007:31:259-67.

112. Silva MC, Meira ZM, Gurgel Giannetti J, et al. Myocardial delayed enhancement by magnetic resonance imaging in patients with muscular dystrophy. J Am Coll Cardiol 2007:49:1874-9.

113. Wang ZJ, Reddy GP, Gotway MB, et al. CT and MR imaging of pericardial disease. Radiographics 2003;23(Spec No):S167-80.

114. Francone M, Dymarkowski S, Kalantzi M, et al. Real-time cine MRI of ventricula septal motion: a novel approach to assess ventricular coupling. J Magn Reson Imaging 2005:21:305-9.

115. Francone $\mathbf{M}$, Dymarkowski S, Kalantzi M, et al. Assessment of ventricular coupling with real-time cine MRI and its value to differentiate constrictive pericarditis from restrictive cardiomyopathy. Eur Radiol 2006:16:944-51.

116. Rice HE, Frush DP, Farmer D, et al. Review of radiation risks from computed tomography: essentials for the pediatric surgeon. J Pediatr Surg 2007:42:603-7.

117. Reant $\mathbf{P}$, Lederlin M, Lafitte $\mathrm{S}$, et al. Absolute assessment of aortic valve stenosis by planimetry using cardiovascular magnetic resonance imaging: comparison with transesophageal echocardiography, transthoracic echocardiography, and cardiac catheterisation. Eur J Radiol 2006;59:276-83

118. Meier RA, Hartnell GG. MRI of right atrial pseudomass: is it really a diagnostic problem? J Comput Assist Tomogr 1994;18:398-401.

119. Barkhausen J, Hunold P, Eggebrecht $\mathrm{H}$, et al. Detection and characterization of intracardiac thrombi on MR imaging. AJR Am J Roentgenol 2002:179:1539-44.

120. Mollet NR, Dymarkowski S, Volders W, et al. Visualization of ventricular thrombi with contrast-enhanced magnetic resonance imaging in patients with ischemic heart disease. Circulation 2002;106:2873-6.

121. Srichai MB, Junor C, Rodriguez LL, et al. Clinical, imaging, and pathological characteristics of left ventricular thrombus: a comparison of contrast-enhanced magnetic resonance imaging, transthoracic echocardiography, and transesophageal echocardiography with surgical or pathological validation. Am Heart J 2006;152:75-84.

122. Mohiaddin RH, Kilner PJ, Rees S, et al. Magnetic resonance volume flow and jet velocity mapping in aortic coarctation. J Am Coll Cardiol 1993;22:1515-21.

123. Russo V, Renzulli M, La Palombara C, et al. Congenital diseases of the thoracic aorta. Role of MRI and MRA. Eur Radiol 2006;16:676-84.

124. Steffens JC, Bourne MW, Sakuma H, et al. Quantification of collateral blood flow in coarctation of the aorta by velocity encoded cine magnetic resonance imaging. Circulation 1994;90:937-43

125. Murray JG, Manisali M, Flamm SD, et al. Intramural hematoma of the thoracic aorta: MR image findings and their prognostic implications. Radiology 1997;204:349-55.

126. Grosse-Wortmann L, Al-Otay A, Goo HW, et al. Anatomical and functional evaluation of pulmonary veins in children by magnetic resonance imaging. J Am Coll Cardiol 2007:49:993-1002.

127. Flacke S, Fischer S, Scott MJ, et al. Novel MRI contrast agent for molecular imaging of fibrin: implications for detecting vulnerable plaques. Circulation 2001:104:1280-5. 
128. Sirol M, Aguinaldo JG, Graham PB, et al. Fibrin-targeted contrast agent for improvement of in vivo acute thrombus detection with magnetic resonance imaging. Atherosclerosis 2005;182:79-85.

129. Sirol M, Fuster V, Badimon JJ, et al. Chronic thrombus detection with in vivo magnetic resonance imaging and a fibrin-targeted contrast agent. Circulation 2005;112:1594-600.

130. Lipinski MJ, Amirbekian V, Frias JC, et al. MRI to detect atherosclerosis with gadolinium-containing immunomicelles targeting the macrophage scavenger receptor. Magn Reson Med 2006;56:601-10.

131. Ruehm SG, Corot C, Vogt P, et al. Ultrasmall superparamagnetic iron oxideenhanced MR imaging of atherosclerotic plaque in hyperlipidemic rabbits. Acad Radiol 2002;9(Suppl 1):S143-4.

132. Ruehm SG, Corot C, Vogt P, et al. Magnetic resonance imaging of atherosclerotic plaque with ultrasmall superparamagnetic particles of iron oxide in hyperlipidemic rabbits. Circulation 2001;103:415-22

133. Sirol M, Itskovich W, Mani V, et al. Lipid-rich atherosclerotic plaques detected by gadofluorine-enhanced in vivo magnetic resonance imaging. Circulation 2004; 109:2890-6.

134. Kuehne T, Saeed M, Higgins CB, et al. Endovascular stents in pulmonary valve and artery in swine: feasibility study of MR imaging-guided deployment and postinterventional assessment. Radiology 2003;226:475-81.

135. Raman VK, Karmarkar PV, Guttman MA, et al. Real-time magnetic resonanceguided endovascular repair of experimental abdominal aortic aneurysm in swine. J Am Coll Cardiol 2005;45:2069-77.

136. Raval AN, Telep JD, Guttman MA, et al. Real-time magnetic resonance imaging guided stenting of aortic coarctation with commercially available catheter devices in Swine. Circulation 2005;112:699-706.
137. Schalla S, Saeed M, Higgins CB, et al. Balloon sizing and transcatheter closure of acute atrial septal defects guided by magnetic resonance fluoroscopy: assessment and validation in a large animal model. J Magn Reson Imaging 2005;21:204-11.

138. McVeigh ER, Guttman MA, Lederman RJ, et al. Real-time interactive MRI-guided cardiac surgery: aortic valve replacement using a direct apical approach. Magn Reson Med 2006:56:958-64.

139. Bulte JW, Douglas T, Witwer B, et al. Magnetodendrimers allow endosoma magnetic labeling and in vivo tracking of stem cells. Nat Biotechnol 2001; 19:1141-7.

140. Dick AJ, Guttman MA, Raman VK, et al. Magnetic resonance fluoroscopy allows targeted delivery of mesenchymal stem cells to infarct borders in Swine. Circulation 2003:108:2899-904.

141. Kraitchman DL, Heldman AW, Atalar E, et al. In vivo magnetic resonance imaging of mesenchymal stem cells in myocardial infarction. Circulation 2003; 107:2290-3

142. Hendel RC, Patel MR, Kramer CM, et al. ACCF/ACR/SCCT/SCMR/ASNC/NASCI/ SCAI/SIR 2006 appropriateness criteria for cardiac computed tomography and cardiac magnetic resonance imaging: a report of the American College of Cardiology Foundation Quality Strategic Directions Committee Appropriateness Criteria Working Group, American College of Radiology, Society of Cardiovascular Computed Tomography, Society for Cardiovascular Magnetic Resonance, American Society of Nuclear Cardiology, North American Society for Cardiac Imaging, Society for Cardiovascular Angiography and Interventions, and Society of Interventional Radiology. J Am Coll Cardiol 2006;48:1475-97

\section{Images in cardiology}

\section{Multi-perforated atrial septum}

A 61-year-old woman was referred owing to recent-onset, moderate dyspnoea on exertion. On physical examination the patient was in atrial fibrillation. The second heart sound was widely split with a prominent pulmonary component that was, however, moving with inspiration. A systolic ejection murmur was heard at the upper left sternal edge and there was also the impression of a diastolic rumble at the lower left sternal border. The patient was pink and the jugular venous pressure was not raised but there was mild bilateral ankle oedema.

Trans-thoracic echocardiography that had been performed elsewhere demonstrated a central jet through the atrial septum and the condition was deemed to be a typical atrial secundum atrial septal defect (ASD). On transoesophageal echocardiography, multiple jets were seen (panel A). The right ventricle was dilated, there was pulmonary hypertension (50 mm Hg) and the Op/Os was 2. The patient was referred for surgical repair. A multiperforated membranous atrial septum was found with a functional total cross-sectional area of approximately $3 \mathrm{~cm}^{2}$ (panel B). It was resected and replaced by a patch of autologous pericardium.

Multiple ASDs are unusual, found in less than $8 \%$ of diagnosed cases of ASD, ${ }^{1}$ and can be missed on trans-thoracic echocardiography. The effective shunt is the additive shunt of all the little holes.

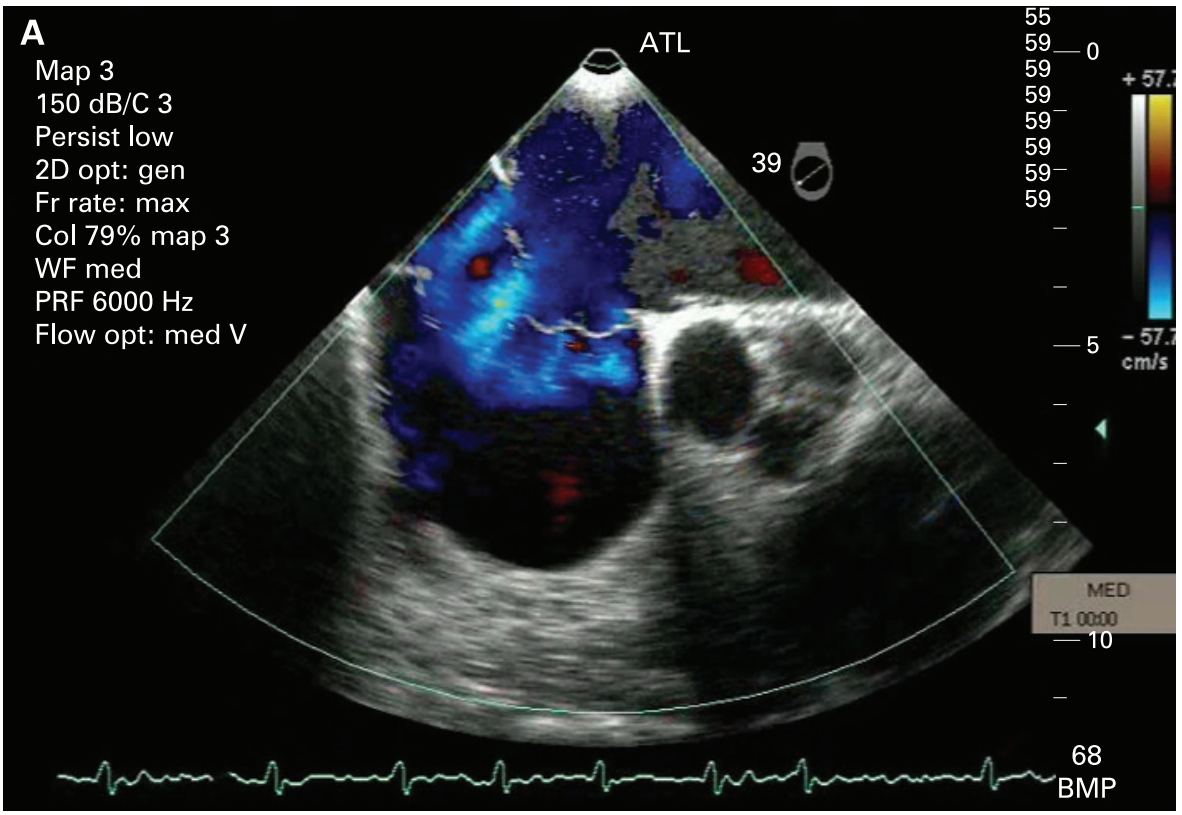

D G Katritsis, M Aronis

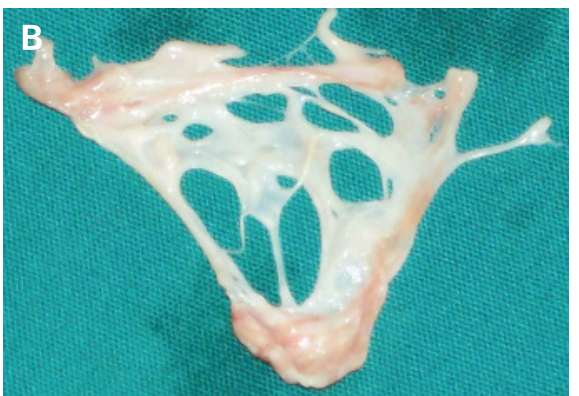

dkatritsis@euroclinic.gr

Ethics approval: Ethics committee approval obtained. Heart 2008;94:1495. doi:10.1136/hrt.2008.144121

\section{REFERENCE}

. Podnar T, Martanovic P, Gavora P, et al

Morphological variations of secundum-type atrial septal defects: feasibility for percutaneous closure using Amplatzer septal occluders. Catheter Cardiovasc Interv 2001:53:386-91. 